\title{
Thoracic Paravertebral Extramedullary Hematopoiesis
}

\author{
Satoshi Hamada ${ }^{1}$, Eiichi Hayashi ${ }^{2}$ and Mitsuhiro Tsukino ${ }^{1}$
}

Key words: extramedullary hematopoiesis, hemolytic anemia

(Intern Med 57: 3495-3496, 2018)

(DOI: 10.2169/internalmedicine.0755-17)

(A)

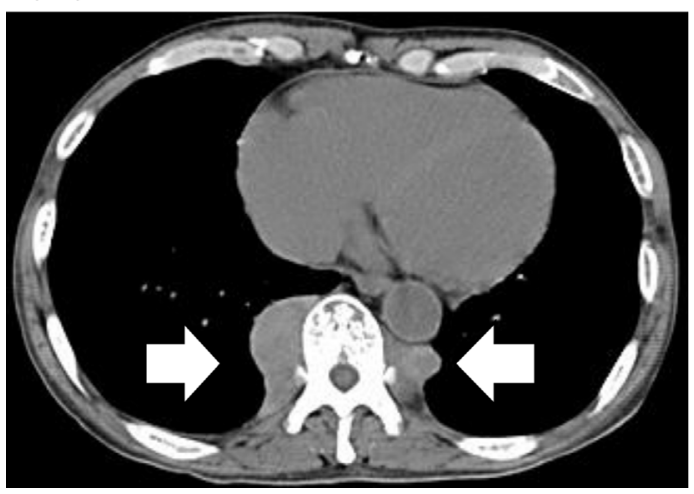

(B)

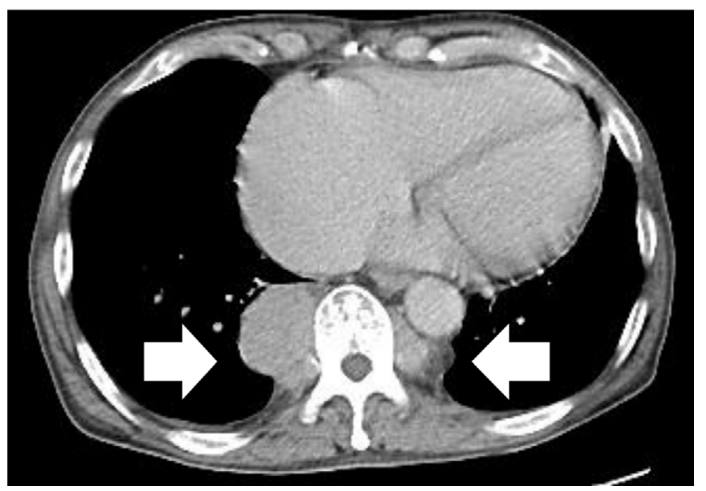

Picture 1.

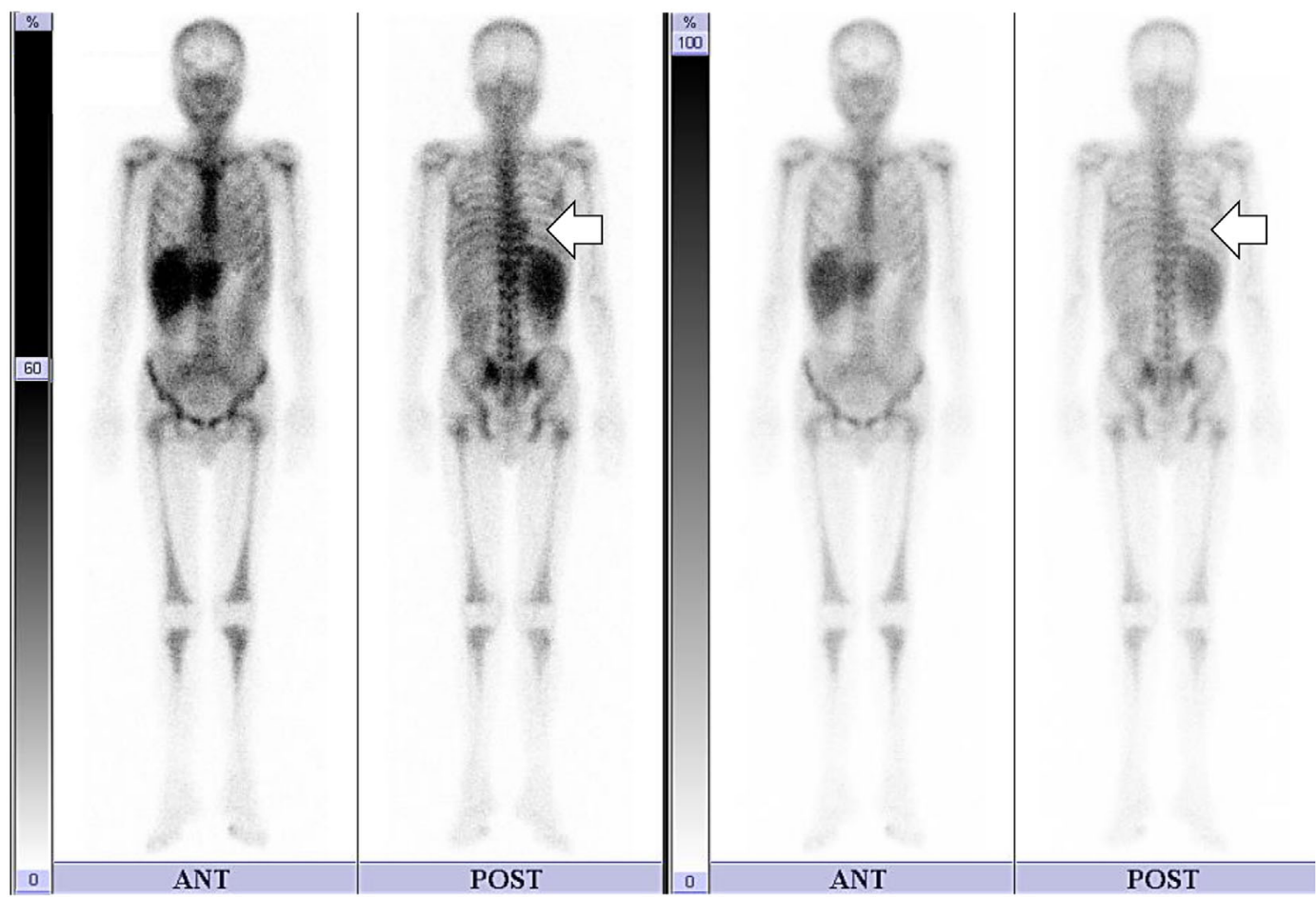

Picture 2.

${ }^{1}$ Department of Respiratory Medicine, Hikone Municipal Hospital, Japan and ${ }^{2}$ Department of Thoracic Surgery, Hikone Municipal Hospital, Japan

Received: December 29, 2017; Accepted: May 1, 2018; Advance Publication by J-STAGE: August 10, 2018

Correspondence to Dr. Satoshi Hamada, sh1124@kuhp.kyoto-u.ac.jp 


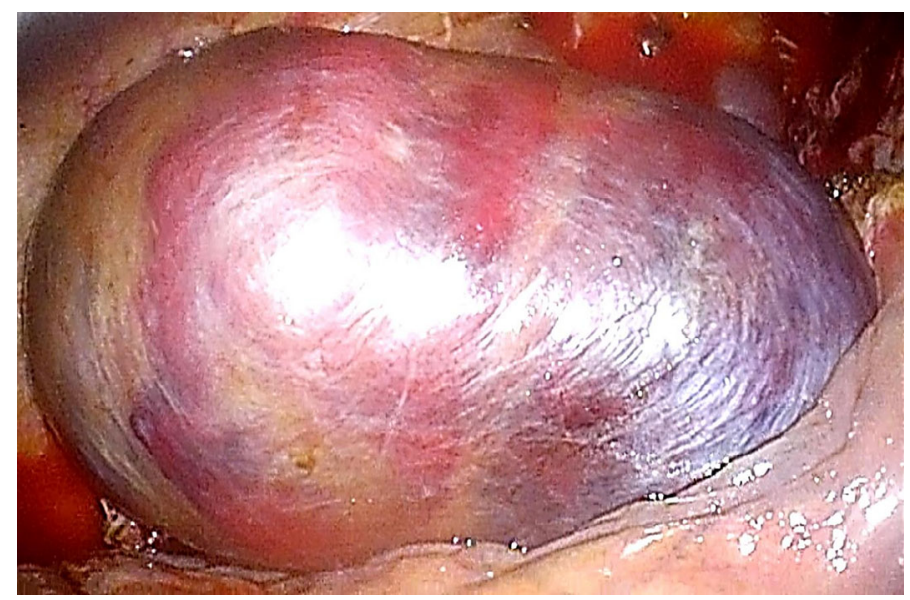

Picture 3.

(A)

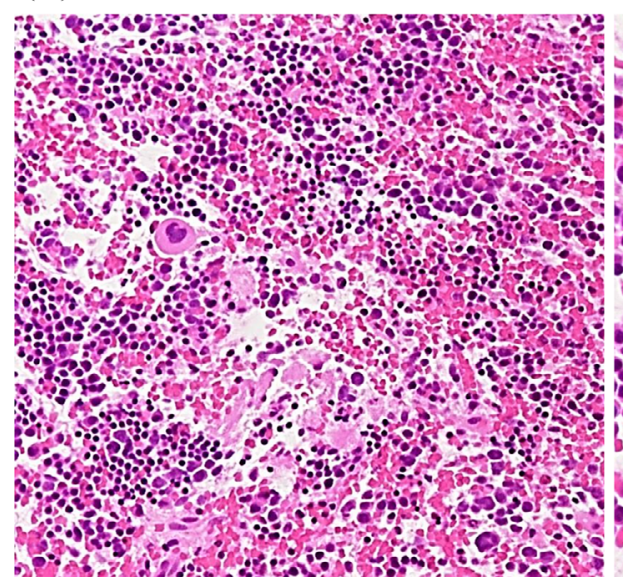

(B)

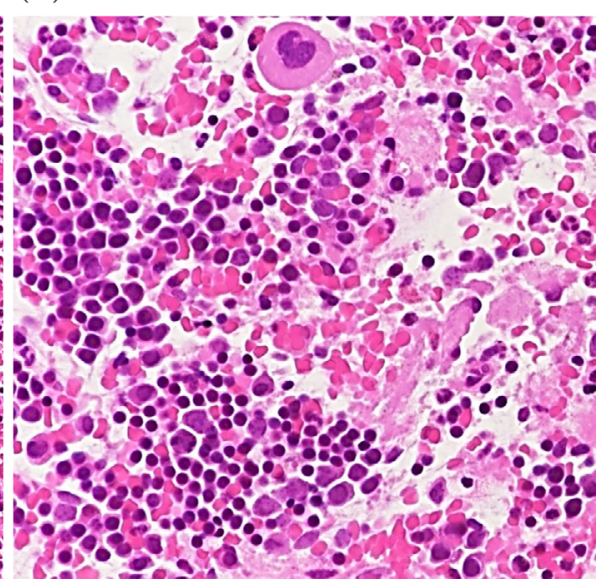

Picture 4.

A 74-year-old man was diagnosed with unexplained normocytic/normochromic hemolytic anemia with negative indirect/direct Coombs tests and without any morphological changes at 67 years of age. At that time, computed tomography (CT) revealed bilateral masses in the lower thoracic paravertebral regions (Picture 1A). At 74 years of age, he had exertional dyspnea and CT revealed the increased size of the mass (Picture 1B). Indium-111-chloride-transferrin scintigraphy demonstrated the uptake of these masses (Picture 2). We performed a needle biopsy of the mass on the right side using video-assisted thoracoscopy without any complications (Picture 3). The biopsy specimen revealed hematopoietic cells composed of megakaryocytes, erythroblasts, and myeloid cells (Picture 4). Finally, he was diagnosed with extramedullary hematopoiesis (EMH).

EMH may sometimes manifest as a tumor-like mass, as occurred in our case (1). In this situation, we should care- fully perform a biopsy, which is associated with a risk of catastrophic hemorrhage, to exclude malignant diseases (2).

The authors state that they have no Conflict of Interest (COI).

\section{References}

1. Bolaman Z, Polatli M, Cildag O, Kadiköylü G, Culhaci N. Intrathoracic extramedullary hematopoiesis resembling posterior mediastinal tumor. Am J Med 112: 739-741, 2002.

2. Haidar R, Mhaidli H, Taher AT. Paraspinal extramedullary hematopoiesis in patients with thalassemia intermedia. Eur Spine J 19: 871-878, 2010.

The Internal Medicine is an Open Access journal distributed under the Creative Commons Attribution-NonCommercial-NoDerivatives 4.0 International License. To view the details of this license, please visit (https://creativecommons.org/licenses/ by-nc-nd/4.0/).

(C) 2018 The Japanese Society of Internal Medicine Intern Med 57: 3495-3496, 2018 